\title{
PerCursos
}

\section{População em perigo: rios urbanos e áreas vulneráveis a inundações - o caso do município de União dos Palmares, Alagoas, Brasil}

\begin{abstract}
Resumo
O presente trabalho teve como objetivo mensurar as áreas vulneráveis no município alagoano de União dos Palmares, em decorrência da enchente no ano de 2010, através do diagnóstico ambiental do Rio Mundaú. Na pesquisa foram utilizadas informações bibliográficas sobre as temáticas abordadas, levantamentos de matérias publicadas na imprensa local e nacional sobre essa inundação e, paralelamente, foram coletados dados junto à Secretaria Municipal de Meio Ambiente e à Secretaria Estadual de Meio Ambiente e Recursos Hídricos. O levantamento das áreas afetadas foi realizado mediante visitas em campo, nas quais foram realizadas entrevistas para saber até onde as águas atingiram e, com a utilização de GPS, foram coletados os pontos para a confecção do mapa de área afetada pelo transbordamento da água do Rio Mundaú. A ferramenta do mapeamento foi a resposta que os pesquisadores produziram para contribuir com a gestão pública municipal, visto que o planejamento territorial do município está desalinhado em relação ao plano diretor e ao código de postura, sendo que esses documentos não fazem menções sobre áreas ribeirinhas, proibindo, por exemplo, essas áreas de uso e ocupação por qualquer tipo de edificação, seja de moradia ou de comércio.
\end{abstract}

Palavras-chave: Bacias hidrográficas. Inundações. Administração pública. Mundaú, Rio. União dos Palmares (AL).
José Lidemberg de Sousa Lopes

Doutor em Geografia pela

Universidade Federal do Ceará -

UFC. Professor da graduação em

Geografia e do Programa de Pós-

Graduação em Dinâmicas

Territoriais e Cultura da

Universidade Estadual de

Alagoas - UNEAL.

Brasil

jlidemberg@yahoo.com.br

\section{Leandra Lourenço Domingos \\ Graduanda em Geografia pela Universidade Estadual de Alagoas - UNEAL, Campus V - Zumbi dos Palmares. Brasil leandrajufra@hotmail.com}

\footnotetext{
Para citar este artigo:

LOPES, José Lidemberg de Sousa; DOMINGOS, Leandra Lourenço. População em perigo: rios urbanos e áreas vulneráveis a inundações - o caso do município de União dos Palmares, Alagoas, Brasil. PerCursos, Florianópolis, v. 21, n.46, p. 113 -135, maio/ago. 2020.
}

DOI: $10.5965 / 1984724621462020113$

http://dx.doi.org/10.5965/1984724621462020113 


\title{
Endangered population: urban rivers and areas vulnerable to flooding - the case of União dos Palmares, Alagoas, Brazil
}

\begin{abstract}
This work aimed to measure the vulnerable areas in the Alagoas municipality of União dos Palmares due to the flood in 2010 through the environmental diagnosis of the Mundaú River. The research used bibliographic information on the topics covered, surveys of stories published in the local and national press about this flood. In parallel, data were collected from the Municipal Department for the Environment and the State Department for the Environment and Water Resources. The survey of the affected areas was carried out through field visits. Interviews were carried out to find out where the waters reached, and with the use of GPS, points were collected for making the map of the area affected by the overflow of water from the Mundaú River. The mapping tool was the answer that the researchers produced to contribute to the municipal public management since the territorial planning of the municipality is not aligned with the master plan and the posture code. These documents do not mention riverside areas, prohibiting, for example, these areas of use and occupation by any type of building, be it housing or commerce.
\end{abstract}

Keywords: Hydrographic basin. Flood. Public policy. Mundaú River. Union of Palmares ( $A L)$. 


\section{Introdução}

O estudo dos rios urbanos é um ponto estratégico para os gestores públicos no que concerne ao planejamento local, de modo que eles percebam esse componente natural com maior atenção, embora muitas vezes a área de rio seja esquecida e negada. A ocupação clandestina e improvisada, a pobreza e a segregação socioespacial criam um contexto de fortes desigualdades sociais ao mesmo tempo em que instituem territórios de riscos onde ocorre a sobreposição de perigos diversos (naturais e sociais) e onde prepondera a vulnerabilidade social atrelada à exposição a vários fenômenos de cunho natural (ALMEIDA, 2010, p. 22).

A ideia deste artigo foi analisar a problemática socioambiental urbana decorrente da ocupação irregular das margens do rio Mundaú e de seus subafluentes, visando identificar as áreas que foram afetadas pela enchente ocorrida na Bacia Hidrográfica do Mundaú no ano de 2010, dando ênfase ao município de União dos Palmares, sendo esse o mais afetado.

O território alagoano é composto por 54 (cinquenta e quatro) bacias hidrográficas - BHs (SEMARH, 2012), dentre as quais se destaca a Bacia Hidrográfica do Rio Mundaú que banha os estados de Pernambuco e de Alagoas, e para este representa cerca de $47,8 \%$ de sua área total, ocupando a parte centro-norte-oriental do estado, com destaque para dois importantes rios, o Paraíba e o Mundaú, sendo este último o objeto de discussão neste trabalho.

No Estado de Alagoas, as enchentes não são um fato novo; desde o século passado, elas são registradas nas bacias hidrográficas dos rios Paraíba e Mundaú. Ao todo, a história nos conta que as enchentes ocorridas na bacia do rio Mundaú ocorreram nos anos de 1914, 1941, 1969, 1989, 2000 e 2010, sendo esta última a catástrofe de maior intensidade. Recentemente, em 30 de março de 2020, a cidade do sertão alagoano de Santana do Ipanema foi acometida por uma grande enchente, que deixou uma parte da população desabrigada e desalojada, além de vários óbitos, mostrando que não só a Zona da Mata pode sofrer com esses efeitos extremos; o sertão também pode ser assolado por esse tipo de catástrofe. 
No que diz respeito aos riscos para a população, as enchentes combinam condições do meio natural (topografia, cobertura vegetal e clima) atreladas às socioeconômicas (demografia, tipologia habitacional, emprego e renda, acesso à educação e serviços de saúde). Esses fatores nos levam a pensar sobre o conceito de vulnerabilidade que está sendo, dia após dia, difundido por pesquisadores de abordagens interdisciplinares. Nesse processo, os grupos populacionais e os espaços geográficos mais vulneráveis são os mais afetados. Em geral, populações que vivem em aglomerados subnormais ocupam terras consideradas inadequadas para uso residencial ou comercial, localizadas em áreas mais baixas, propensas a inundações, e/ou encostas sujeitas a deslizamentos de terra, expondo as pessoas a riscos constantes.

A pesquisa procura trazer a abordagem da percepção ambiental na análise dos riscos e perigos relacionados às enchentes das áreas lindeiras da planície fluvial do rio Mundaú, no município de União dos Palmares.

\section{Caracterização de União dos Palmares e da Bacia Hidrográfica do Rio Mundaú}

União dos Palmares, localizada na Mesorregião do Leste Alagoano e na Microrregião Geográfica Serrana dos Quilombos, limita-se ao norte com São José da Laje e Ibateguara, ao sul com Branquinha, a leste com Joaquim Gomes e a oeste com Santana do Mundaú. O município tem uma área de 420.658 km² (IBGE, 2010), distante 83 km de Maceió, tendo como principais vias de acesso as rodovias BR 416 e BR 104 (Mapa 1). Em 2010, a população total recenseada foi de 62.358 pessoas (30.171 homens e 32.187 mulheres), sendo a urbana de 47.651, tendo a rural decrescido para 14.707 (IBGE, 2010).

Os dados a seguir foram retirados da Enciclopédia dos municípios de Alagoas do ano de 2012 e mostram que o município faz parte da Área Piloto da Reserva da Biosfera da Mata Atlântica (RBMA) e da Área Estadual de Proteção Ambiental (APA) de Murici, com 116.100 ha, que inclui também os municípios de Branquinha, São José da Laje, 
Colônia Leopoldina, Ibateguara, Novo Lino, Joaquim Gomes e Messias e ainda detém o Sítio Arqueológico da Serra da Barriga.

Mapa 1 - Localização do município de União dos Palmares-AL

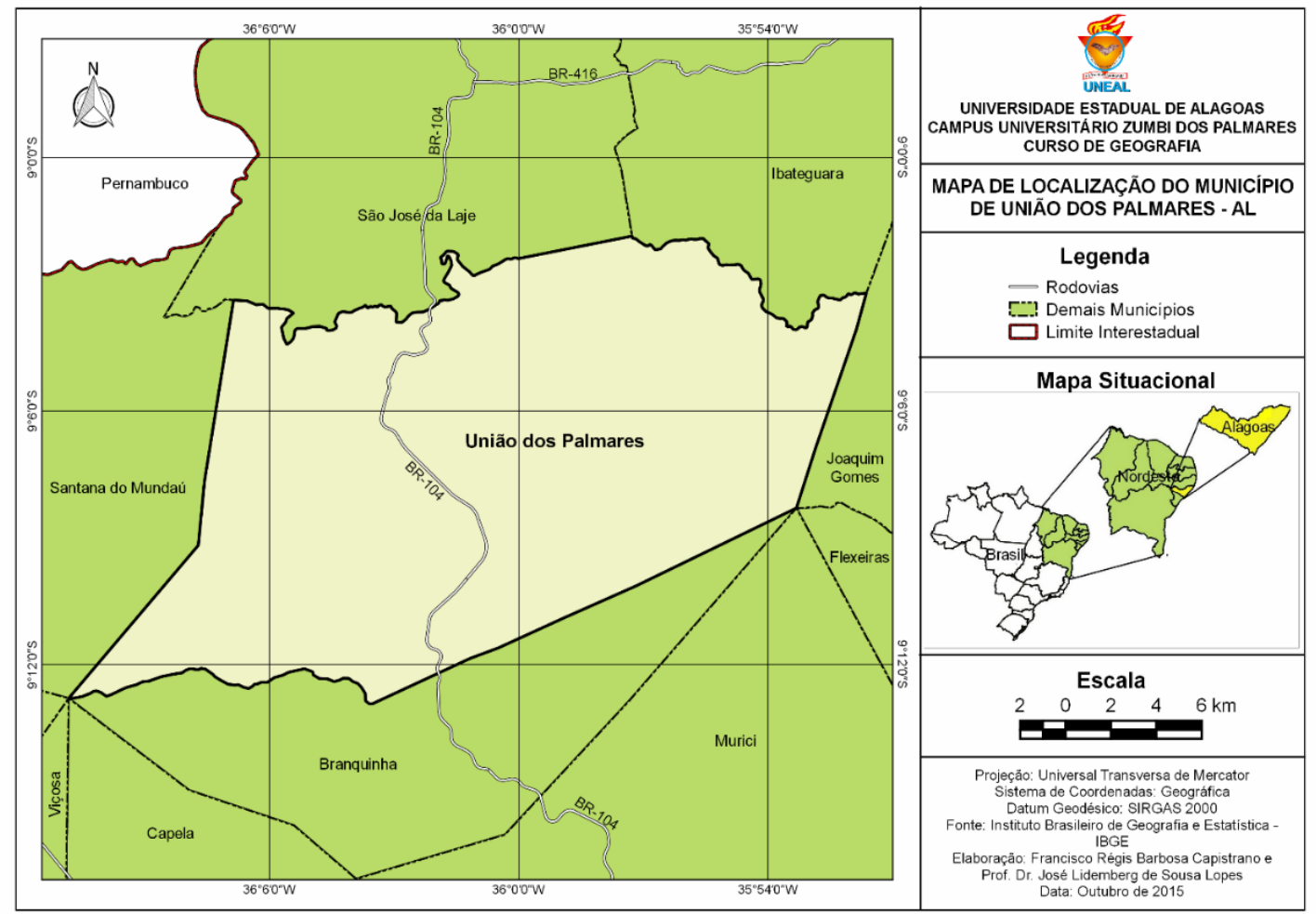

Fonte: Elaborado por José Lidemberg de Sousa Lopes (2015) com base nos dados de Alagoas (2012).

Em relação aos componentes ambientais físicos, o município situa-se geologicamente sobre o Complexo Migmatítico-Granítico que compõe o embasamento do Maciço Pernambuco-Alagoas. O intemperismo ${ }^{1}$ que prepondera e atua na região, e que contribui para as formas de relevo que encontramos no entorno da Bacia Hidrográfica do Mundaú é o físico-químico no qual a prevalência do elemento climático

\footnotetext{
${ }^{1}$ Intemperismo: Conjunto de processos mecânicos, químicos e biológicos que ocasionam a desintegração e decomposição das rochas. O uso do termo intemperismo tem sido combatido por certos autores que preferem o de meteorização, pelos fatos de melhor corresponder ao termo em inglês weathering. Talvez mais feliz que o emprego do termo meteorização seria erosão elementar, tendo em vista que esta constitui a etapa preliminar, ou mesmo, elementar, na realização de qualquer dos outros tipos de erosão (GUERRA, 1978, p. 237).
} 
pluviosidade e temperatura estão presentes no decorrer do ano. As formas abauladas, como a conhecida Serra da Barriga (daí a origem do nome), refúgio dos escravos fugidos no pretérito é um exemplo da contribuição desse processo geomorfológico.

União dos Palmares tem médias térmicas mensais de $22^{\circ} \mathrm{C}$ em julho e agosto e de $25,5^{\circ} \mathrm{C}$ em janeiro e fevereiro. As médias térmicas anuais ficam em torno de $23,5^{\circ} \mathrm{C}$ e a precipitação total é de $1.400 \mathrm{~mm}$, distribuída de forma irregular, com 70\% das chuvas de abril a agosto. O clima é classificado, segundo Thornthwaite, como megatérmico subúmido, com excedente hídrico no inverno e déficit no verão.

Os principais solos encontrados são os gleissolos Amarelos, Vermelho-Amarelos eutróficos, latossolos Vermelho-Amarelo distróficos e, em áreas fluviais, encontramos solos aluviais distróficos e eutróficos e gleissolos distróficos.

O regime fluvial do município é composto pelas bacias hidrográficas (BHs) dos rios Mundaú, Camaragibe e Santo Antônio Grande. As maiores altitudes são encontradas nas serras da Barriga, com 535 metros, e Tavares, com 480 metros.

Vários autores e pesquisadores como Pires, Santos e Del Prette, conceituam bacia hidrográfica como

um conjunto de terras drenadas por um rio principal e seus afluentes". Portanto, é composta de um conjunto de superfícies vertentes e de uma rede de drenagem, formada por cursos de água que confluem até resultar em um leito único no seu exutório. Logo, por ter características bem definidas, a bacia hidrográfica é uma unidade que permite caracterizar e combater os impactos ambientais. (PIRES et al., 2002, p. 17)

Segundo a Secretaria de Recursos Hídricos de Alagoas - SEMARH, o rio Mundaú é o tronco principal da bacia de drenagem, nasce na cidade de Garanhuns, com cerca de $69 \mathrm{~km}$ percorrendo áreas do Estado de Pernambuco e desemboca na lagoa Mundaú, na capital alagoana. A bacia do rio Mundaú possui uma área de $4.126 \mathrm{~km}^{2}$, banhando trinta municípios. Em seu trecho pernambucano, apresenta uma área de $2.155 \mathrm{~km}^{2}$, localizada na Mesorregião do Agreste Pernambucano, onde estão, total ou parcialmente, inseridos territórios de 15 municípios, com uma população de mais de 215.000 habitantes (IBGE, 
2010). Estão situadas no referido trecho pernambucano oito sedes municipais, sendo que quatro municípios estão inseridos totalmente na bacia; são eles: Angelim, Correntes, Palmeirina e São João; e outras quatro sedes municipais inseridas parcialmente na bacia: Caetés, Canhotinho, Lagoa do Ouro e Garanhuns, a maior delas (Mapa 2). Na parte alagoana da bacia, que corresponde à sua metade inferior, a superfície é de $1.971 \mathrm{~km}^{2}$, onde estão, total ou parcialmente, inseridos territórios de 15 municípios da Mesorregião do Leste Alagoano, abrangendo uma população de cerca de 230.000 habitantes. Encontram-se no trecho de Alagoas dez sedes municipais, além de uma pequena parte da zona urbana de Maceió, destacando-se, como principais núcleos urbanos, as cidades de Rio Largo e de União dos Palmares.

Mapa 2 - Localização da Bacia Hidrográfica do Rio Mundaú

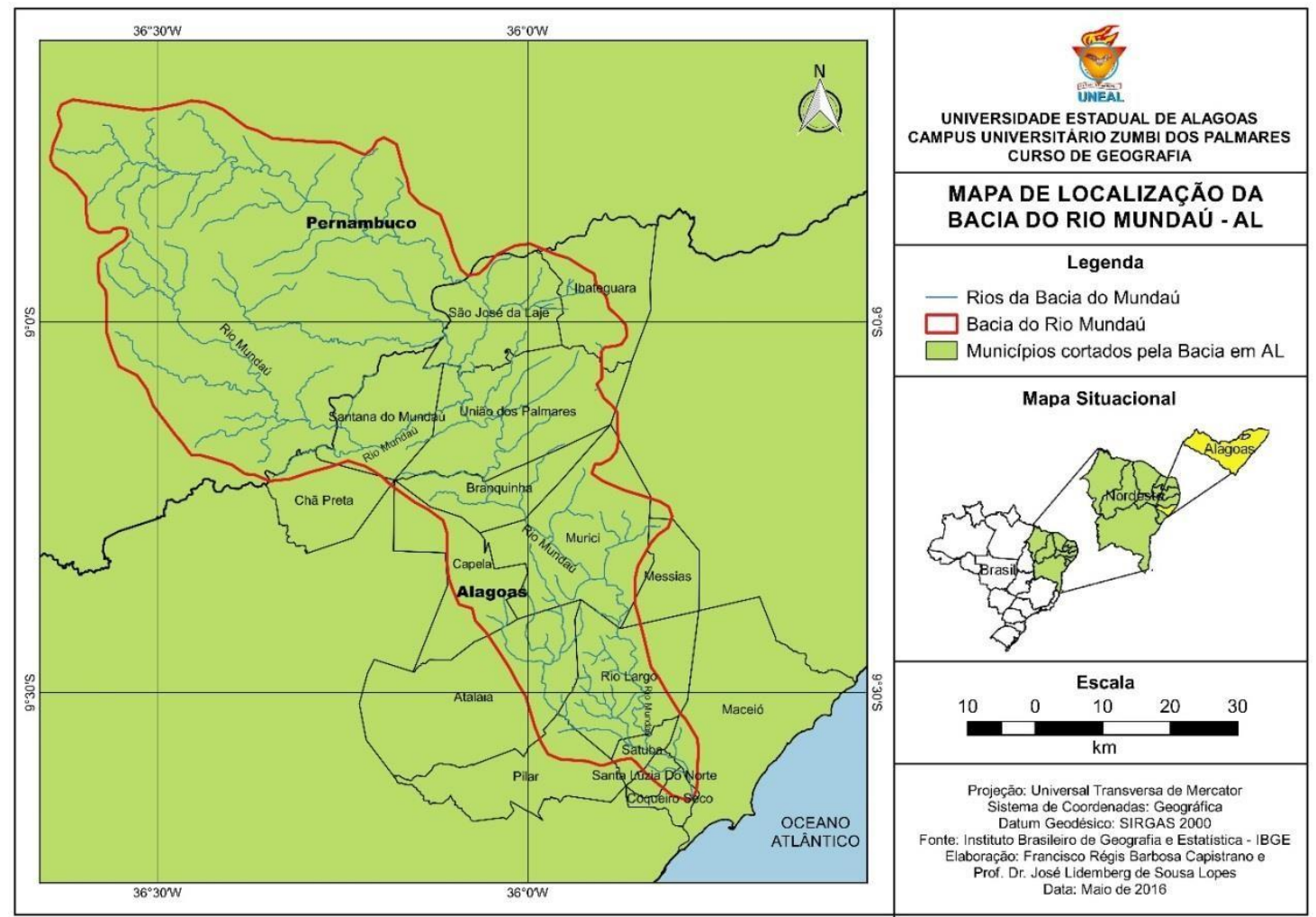

Fonte: Elaborado por José Lidemberg de Sousa Lopes (2016). 
Os principais afluentes do rio Mundaú no estado de Pernambuco são, pela margem direita, riacho Conceição, riacho Salgado, rio Correntes e rio Mundauzinho; e, pela margem esquerda, o rio Canhoto, que deságua no rio Mundaú em território alagoano; é o afluente mais importante e tem, por sua vez, como principal contribuinte o rio Inhaúma.

No subitem a seguir serão tratados os conceitos de enchente e áreas vulneráveis, com base na literatura científica, além de comentadas as matérias publicadas na imprensa local e nacional sobre os temas. Por fim, serão apresentados dados da visita de campo, realizada entre agosto e dezembro de 2015, para localizar as áreas afetadas pelas águas dessa enchente no município de União dos Palmares $(A L)$ e entrevistas ${ }^{2}$ com os antigos moradores que foram afetados pelas inundações provocadas pelas águas do rio Mundaú.

\section{A enchente em União dos Palmares em 17 e 18 de junho de 2010}

As problemáticas das enchentes estão associadas aos eventos extremos, tais como racionamento de energia ou água, enchentes, alagamentos urbanos e limitações de obras hídricas. A predição de eventos de enchente pode ser realizada a partir de estatísticas de amostras do passado e tem como resultado a probabilidade de um valor de precipitação ou vazão igualado ou superado.

Entre os dias 17 e 18 de junho de 2010, os estados de Pernambuco e de Alagoas vivenciaram um fenômeno climático chamado "Ondas de Leste" ou "Distúrbios Ondulatórios de Leste - DOL"3 (figura 1), que foi intensificado pelo aquecimento da temperatura do oceano Atlântico juntamente com a intensificação dos ventos alísios. Isso provocou, em curto espaço de tempo, uma grande quantidade de chuva,

\footnotetext{
${ }^{2}$ As entrevistas foram de caráter observacional e para constatar se águas da enchente de 2010 chegaram às residências dos entrevistados. As entrevistas foram realizadas no período da visita de campo entre agosto e dezembro de 2015.

3 De acordo com informações do Governo do Estado de Pernambuco (Relatório Ação, 2011), esse fenômeno foi caracterizado por uma conjunção de ventos fortes do oceano em direção ao interior do estado, por uma grande concentração de nuvens nas cabeceiras dos rios e por um aquecimento acima do esperado da massa do Oceano Atlântico.
} 
População em perigo: rios urbanos e áreas vulneráveis a inundações - o caso do município de União dos Palmares, Alagoas, Brasil

José Lidemberg de Sousa Lopes, Leandra Lourenço Domingos

concentrada nas proximidades das cabeceiras de vários rios, gerando uma enorme enxurrada que atingiu cidades ribeirinhas de Pernambuco e de Alagoas.

Figura 1 - Distúrbios Ondulatórios de Leste que atingiram o leste alagoano e pernambucano em junho de 2010

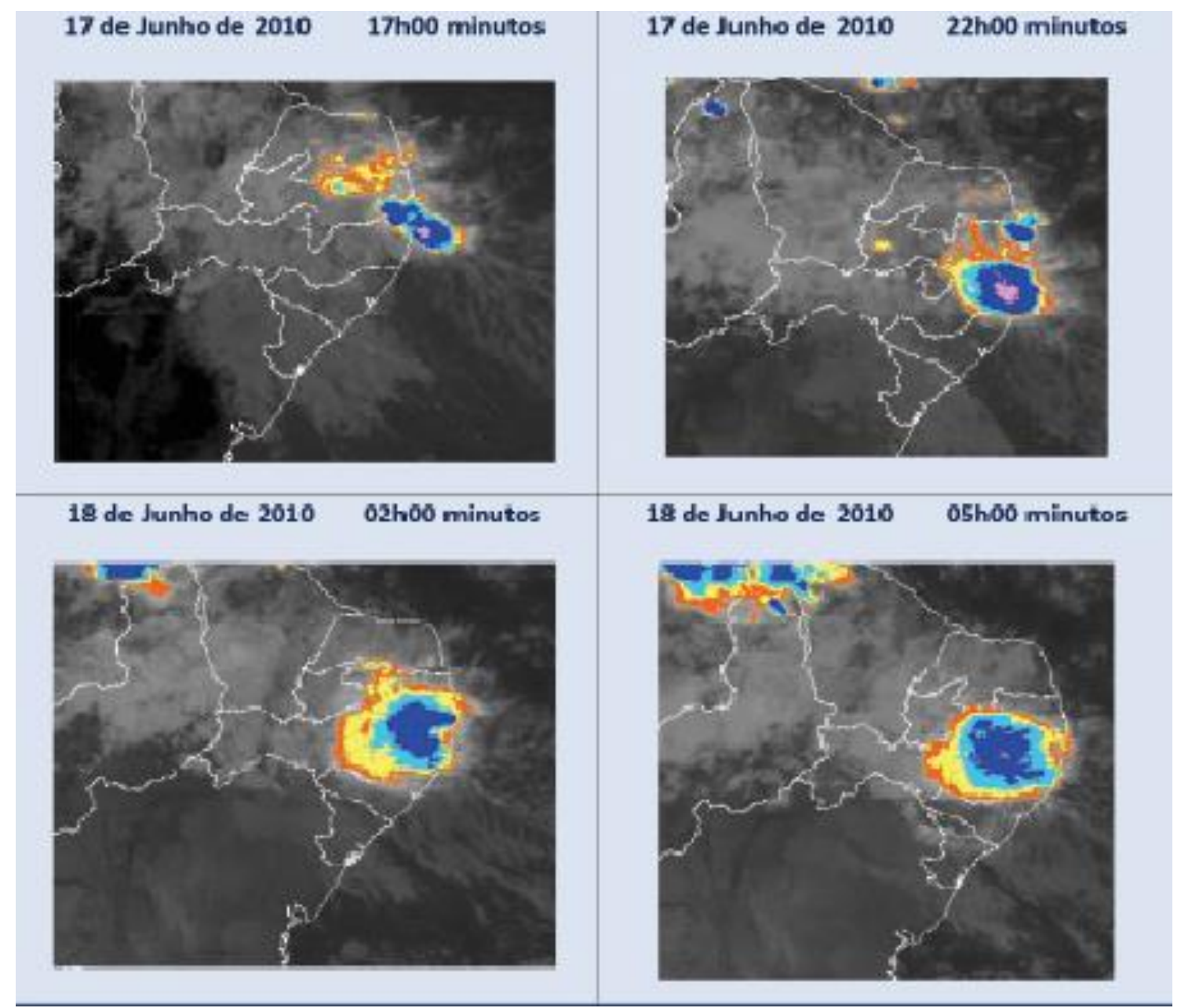

Fonte: CPTEC/INPE, 2010.

Segundo Fragoso Júnior et al (2010, p. 9), os registros pluviométricos do mês de junho de 2010 mostram um período de chuvas muito superiores à média, conforme mostrado nas isoietas da figura 2.

Para ilustrar, o posto Garanhuns registrou 283,6 mm de chuva entre os dias $1^{\circ}$ e 19 de junho, para uma média mensal histórica de $120 \mathrm{~mm}$. Os primeiros cinco dias do mês 
foram bastante chuvosos, seguidos de um período de menor umidade e, a partir do dia 12, novamente um período bastante chuvoso.

Figura 2 - Isoietas de precipitação para os dias $1^{\circ}$ ao $19^{\circ}$ de junho de 2010

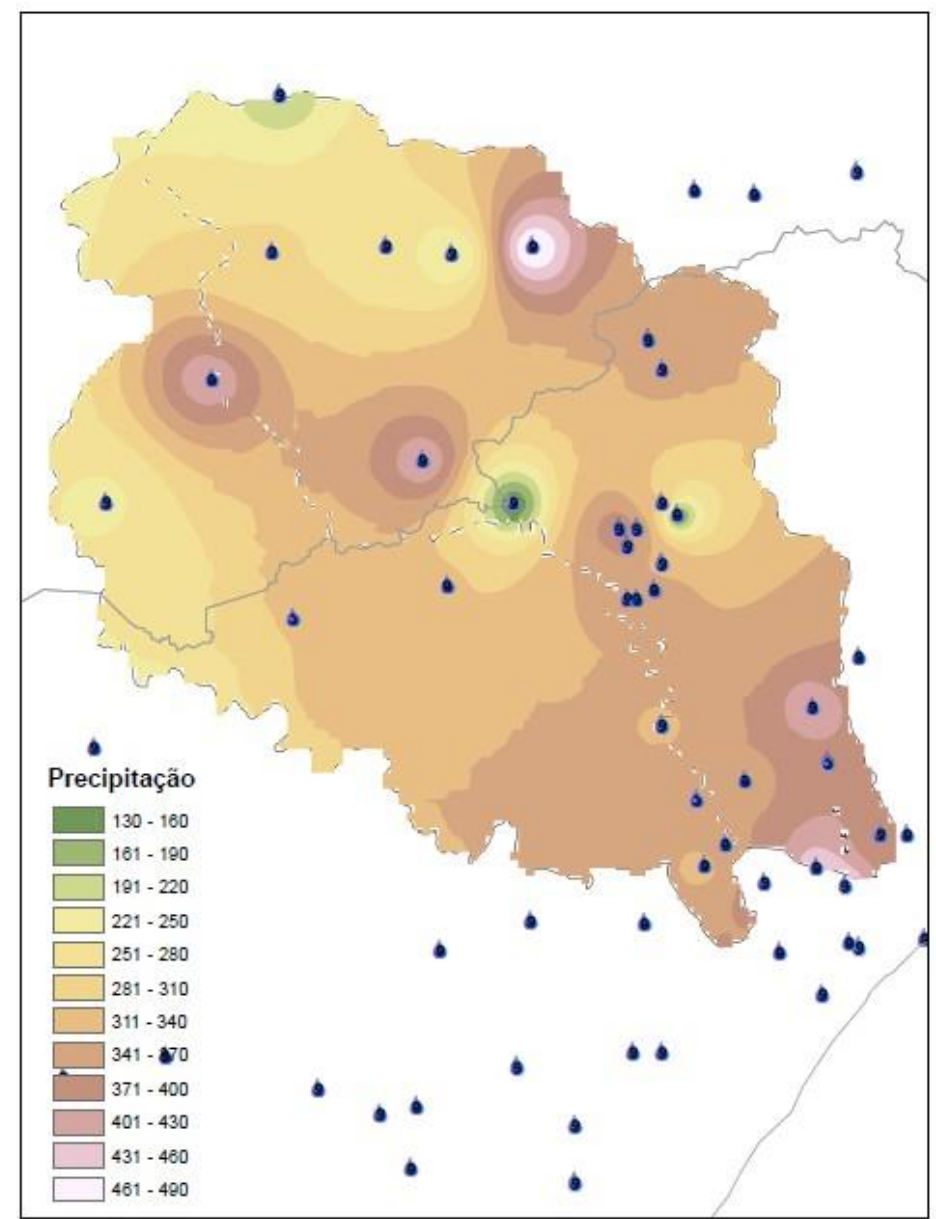

Fonte: Fragoso Júnior et al, 2010, p. 9.

Essas chuvas foram o incremento catastrófico para a enchente ocorrida em União dos Palmares e municípios que fazem parte da bacia do Mundaú, a qual resultou em amplos e intensos impactos, disparando diversas medidas emergenciais, envolvendo ações do Corpo de Bombeiros, Defesa Civil, Exército, Força Nacional, Forças Armadas, Polícia Militar, várias secretarias municipais e estaduais, com destaque para a Secretaria de Saúde do Estado de Alagoas. Também houve uma forte mobilização da sociedade 
civil e dos meios de comunicação para arrecadação de donativos para a população palmarina.

Tal desastre acarretou prejuízos ao ecossistema local e perdas e danos imensuráveis à população. Bastaram três dias de intensa pluviosidade para que o Estado de Alagoas declarasse vários municípios em estado de alerta, sendo 26 em estado de calamidade pública e 34 em estado de emergência. Os municípios de Murici, Rio Largo, Branquinha, União dos Palmares e Santana do Mundaú foram seriamente afetados pela inundação na bacia do rio Mundaú (ver tabela 1).

Tabela 1 - $\mathrm{N}^{\circ}$ de desalojados, desabrigados, feridos, enfermos e mortos, por município, em consequência da inundação ocorrida em Alagoas em 2010

\begin{tabular}{|l|c|c|c|c|c|c|}
\hline Município & Desalojados & Desabrigados & Feridos & Enfermos & Mortos & $\begin{array}{l}\text { População } \\
\text { afetada }\end{array}$ \\
\hline Atalaia & 2.992 & - & - & - & - & 2.992 \\
\hline Branquinha & 3.114 & 494 & 421 & 139 & 6 & 4.174 \\
\hline Cajueiro & 3.510 & 411 & 52 & 34 & - & 4.007 \\
\hline Capela & 180 & 279 & 2 & 14 & - & 475 \\
\hline Ibateguara & 234 & - & - & - & - & 234 \\
\hline Jacuípe & 725 & 153 & - & - & - & 878 \\
\hline $\begin{array}{l}\text { Joaquim } \\
\text { Gomes }\end{array}$ & 358 & 81 & - & 151 & 1 & 591 \\
\hline Jundiá & 258 & 30 & - & - & - & 288 \\
\hline $\begin{array}{l}\text { Matriz de } \\
\text { Camaragibe }\end{array}$ & 2.500 & 1.198 & - & - & - & 3.698 \\
\hline Murici & 7.000 & 1.864 & 154 & 802 & 9 & 9.829 \\
\hline Paulo Jacinto & 585 & 488 & 21 & 12 & 1 & 1.107 \\
\hline Quebrangulo & 2.504 & 2.296 & 16 & - & - & 4.816 \\
\hline Rio Largo & 4.000 & 6.000 & 123 & 69 & 9 & 10.201 \\
\hline $\begin{array}{l}\text { Santana do } \\
\text { Mundaú }\end{array}$ & 2.582 & 3.758 & 70 & 40 & 2 & 6.452 \\
\hline $\begin{array}{l}\text { São José da } \\
\text { Laje }\end{array}$ & 3.930 & 703 & - & - & - & 4.633 \\
\hline $\begin{array}{l}\text { São Luiz do } \\
\text { Quintude }\end{array}$ & 1.755 & 305 & - & - & - & 2.060 \\
\hline
\end{tabular}




\begin{tabular}{|l|c|c|c|c|c|c|}
\hline $\begin{array}{l}\text { São Miguel } \\
\text { dos Campos }\end{array}$ & 3.000 & 420 & 5 & - & - & 3.425 \\
\hline Satuba & 644 & 15 & - & - & - & 659 \\
\hline $\begin{array}{l}\text { União dos } \\
\text { Palmares }\end{array}$ & 2.645 & 8.836 & 220 & 132 & 8 & 11.841 \\
\hline Viçosa & 500 & 1.256 & 47 & - & - & 1.803 \\
\hline Total & 43.016 & $\mathbf{2 8 . 5 8 7}$ & $\mathbf{8 9 1}$ & 907 & 36 & 74.163 \\
\hline
\end{tabular}

Fonte: Banco Mundial, 2012.

A tabela acima mostra que o município mais afetado foi União dos Palmares, que teve 2.645 desalojados, 8.836 desabrigados, 220 feridos, 132 enfermos e 8 mortos, somando 11.841 pessoas afetadas por essa enchente.

Aproximadamente 1,5 milhão de pessoas vivia nos municípios afetados pelas chuvas, representando cerca de 50\% da população residente no Estado de Alagoas. De acordo com o Relatório de Avaliação de Perdas e Danos do Banco Mundial (2012), aproximadamente 270 mil pessoas foram afetadas, das quais 44 mil ficaram desalojadas e 28 mil desabrigadas.

Segundo relatos dos moradores,

a força das águas naqueles dias do mês de junho de 2010 varreu as casas que ficavam próximas às margens direita e esquerda do rio Mundaú. Esses dias foram de pânico e desespero para a população que ali se encontrava. (SILVA, 2015, informação verbal)

Outro relato foi

as águas subiram rapidamente e muitos só conseguiram sair das casas com as vestimentas que estavam no corpo. As casas, e tudo que estava no interior delas, foram arrastadas pela correnteza das águas do rio, que parecia um 'monstro' de braços abertos e uivando. (LOPES, 2015, informação verbal), como demonstrado na figura 3 . 
Figura 3 - Vista da destruição da enchente do Rio Mundaú no município de União dos

Palmares em 2010

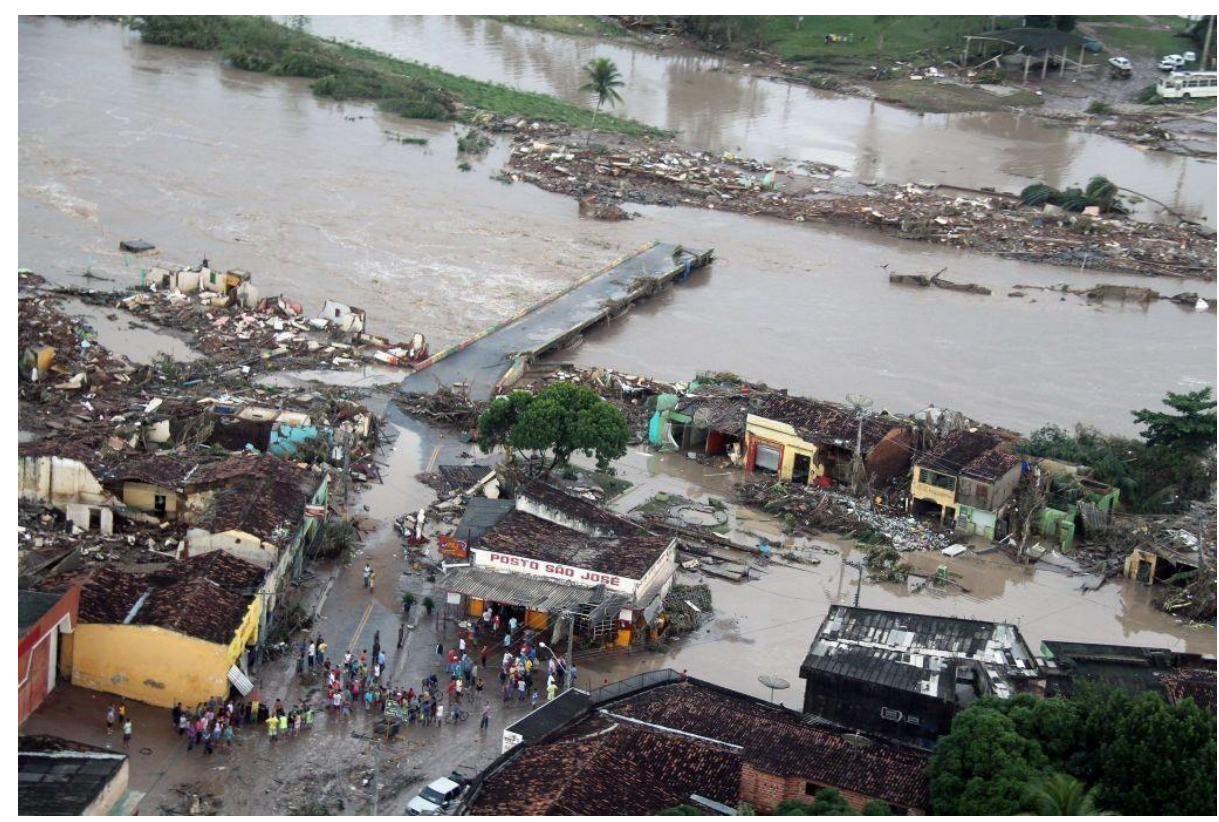

Fonte: Walter e Milan (2010, p. 1).

Autores como Tucci (2008, pp. 104-105) afirmam que as enchentes em áreas urbanas são consequência de dois processos, que ocorrem isoladamente ou de forma integrada:

1. Urbanização — são as enchentes provocadas pela urbanização;

2. Enchentes em áreas ribeirinhas: as enchentes naturais que atingem a população que ocupa os leitos de rios por falta de planejamento do uso do solo.

O autor reforça que a primeira é caracterizada pelo aumento de sua frequência e magnitude devido à ocupação do solo com superfícies impermeáveis e rede de condutos de escoamentos. Adicionalmente, o desenvolvimento urbano pode produzir obstruções ao escoamento como aterros e pontes, drenagens inadequadas e obstruções ao escoamento junto a condutos e assoreamento. O segundo processo são as enchentes em áreas ribeirinhas, as quais o autor afirma que são de ordem natural, atingindo a população que ocupa o leito maior dos rios. Essas enchentes ocorrem, principalmente, pelo processo natural no qual o rio ocupa seu leito maior, de acordo com os eventos 
extremos, em média com o tempo de retorno de ordem de dois anos. Abaixo, segue a figura 4, dos tipos de leitos de um rio.

Figura 4 - Tipos de Leitos fluviais, demonstrando áreas em que são proibidas a ocupação de imóveis
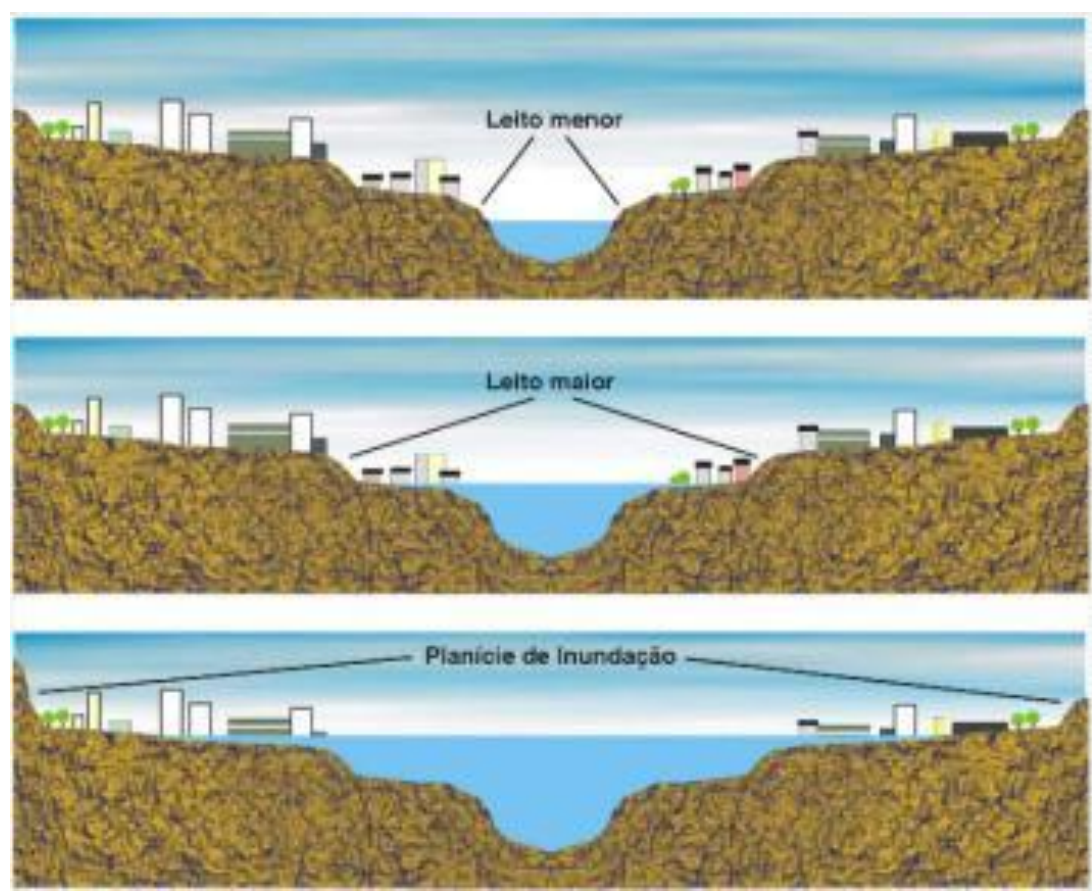

Fonte: Shimabuku, P. (2018, p.1).

Nesse contexto, as enchentes ocorrem quando o escoamento atinge níveis superiores ao leito menor atingindo o leito maior. As cotas do leito maior identificam a magnitude das inundações e seu risco. Os impactos das enchentes ocorrem quando essa área de risco é ocupada pela população, conforme a figura anterior. Esse tipo de evento geralmente ocorre em bacias médias e grandes $\left(>100 \mathrm{~km}^{2}\right)$, e se observarmos, a bacia do Mundaú se enquadra nessa conceituação de Tucci, por possuir uma área de $4.126 \mathrm{~km}$.

As enchentes que ocorreram em União dos Palmares em 2010 são de ordem natural, isto é, enchente ribeirinha, na qual o rio ocupa o seu leito maior, de acordo com os eventos chuvosos extremos, em média com tempo de retorno superior a dois anos. Tais enchentes são geralmente constituídas por cheias temporárias, sem 
transbordamento, porém as que ocorreram nesses dias de junho de 2010 não seguiram essa caracterização. O canal de drenagem do rio atingiu a cota máxima em sua vazão, que acarretou inundações nas áreas da planície fluvial do Mundaú.

Devido ao evento climático, distúrbios ondulatórios de leste, que ocorreu no mês de junho de 2010 na bacia do rio Mundaú, em um só dia as chuvas mínimas foram de 130 $\mathrm{mm}$ e a máxima chegando a $180 \mathrm{~mm}$, o que mostra a magnitude desse evento. Conforme verificadas na figura 1, apresentaram-se mudanças de massas de ar na zona de convergência intertropical para os distúrbios ondulatórios de leste. Esse último, ocasionando uma conjunção de ventos fortes que saíram do oceano Atlântico em direção ao interior dos estados alagoano e pernambucano.

As cabeceiras dos rios receberam elevadas precipitações e, por conta de um aquecimento anormal das águas do Atlântico, a bacia hidrográfica do Mundaú teve seus níveis históricos de vazão superados, ocasionando uma rápida elevação de lâmina d’água e o extravasamento do seu leito e a enchente em vários municípios.

As enchentes resultam da combinação entre dimensões bióticas e abióticas (topografia, cobertura vegetal e clima, por exemplo) e socioeconômicas (densidade populacional e situação das moradias, emprego e renda, acesso à educação e serviços de saúde, por exemplo). Esses componentes, mal conectados, são ingredientes perfeitos para as mais diversas calamidades naturais, como as enchentes que levam às inundações e aos alagamentos das ruas que ocorreram nos perímetros urbanos do município de União dos Palmares (FREIRE et al, 2014).

Os impactos das enchentes sobre a população são causados, principalmente, pela ocupação inadequada do espaço urbano. Essas condições ocorrem, em geral, devido às seguintes ações:

a) loteamentos indevidos. Como no Plano Diretor Urbano da quase totalidade das cidades brasileiras não existe nenhuma restrição quanto ao loteamento de áreas de risco de inundação, a sequência de anos sem enchentes é razão suficiente para que empresários loteiem áreas inadequadas;

b) invasão de áreas ribeirinhas que pertencem ao poder público pela população 
de baixa renda;

c) ocupação de áreas de médio risco, que são atingidas com frequência menor, mas que, quando o são, sofrem prejuízos significativos.

Nesse processo, os grupos populacionais que encontramos nessa área lindeira a rio Mundaú são de pessoas cuja escolaridade ainda é um grande dilema e as chefes de família necessitam de ajudas dos programas assistencialistas do governo federal, como o Bolsa Família. As crianças, ao utilizarem os rios para lazer, acabam contraindo doenças parasitárias, como giardíase; além do mais, a água do rio serve para lavar animais. Enfim, as populações que vivem nessas áreas vulneráveis são extremamente carentes, sem nenhuma perspectiva de melhoria por parte dos órgãos gestores. A senhora Lourdes Ribeiro, de 52 anos, relatou em uma das entrevistas que "os meninos vão tomar banho no rio porque aqui não foi construído nada para o lazer. Então, o rio é o lazer das crianças".

Considerando que enchentes combinam os processos naturais (como uma chuva forte ou a elevação do nível de um rio) com socioeconômicos, a definição de vulnerabilidade encaixa-se bem nessa discussão. De acordo com Lopes (2013), vulnerabilidade é a incapacidade de sobrevivência de uma pessoa ou de um grupo de pessoas; domicílios que ficam expostos a riscos, mediante resposta do meio interno em detrimento do meio externo. Tal incapacidade para dar respostas, a chamada resiliência, é ainda um grande nó nos estudos de áreas afetadas por riscos, sejam eles sociais ou ambientais.

O autor citado acima salienta que a vulnerabilidade é determinada por fatores ou processos de ordens físicas, sociais, econômicas e ambientais, que aumentam a suscetibilidade ou a fragilidade de uma comunidade que nela está inserida e que venha a sofrer impactos consequentes de desastres de feitos extremos, como enchente ou seca.

Em convergência com Lopes (2013), os autores Penna e Ferreira (2014, p. 26) definem a vulnerabilidade como um risco social, caracterizando-se pela concentração de precariedade (ou falta) de serviços coletivos e de investimentos públicos em 
infraestruturas (os ativos e as estruturas de oportunidades), que desse modo provocam a desproteção social das comunidades mais carentes.

As estruturas de oportunidade são oferecidas pelo Estado, pelo mercado e pela sociedade. O Estado é quem atua de forma mais significativa, por promover as políticas de infraestrutura urbana e viária, as políticas sociais (habitação, escolas e creches, saneamento básico) e econômicas (créditos, mercado de trabalho, financiamento à produção). As estruturas de oportunidades estão relacionadas entre si, pois facilitam o acesso a outras oportunidades, bens e serviços. As estruturas de oportunidade constituem as "fontes para o acesso aos ativos" (KAZTMAN; FILGUEIRA, 2006, p. 72).

Como já indicado, a enchente é um fenômeno geográfico excepcional, advindo, por exemplo, de fatores de ordem climática. Assim, regiões e populações vulneráveis são aquelas que podem ser atingidas por algum evento desse tipo e que, adicionalmente, não possuem condições para suportá-los (SOUZA; ZANELLA, 2010, p. 19). E, se fizermos um link da citação anterior com o objeto da pesquisa, verificaremos que a enchente que ocorreu em União dos Palmares foi causada pelos volumes de chuvas excepcionais nos dias 17 e 18 junho de 2010 e as complicações decorrentes da vulnerabilidade da população atingida, como a ocupação irregular do leito do rio, foi o estopim para que as famílias que ali residiam acabassem perdendo tudo que conquistaram durante anos, além da saúde emocional que foi afetada com essa catástrofe.

Complementando o raciocínio dos autores citados acima, Deschamps (2004) afirma que, por suas características geomorfológicas ou por sua localização geográfica, certas áreas são ameaçadas por tais eventos. No caso das enchentes no município de União dos Palmares, as moradias que estão às margens do rio Mundaú e seus subafluentes são as mais atingidas, pois é nesses ambientes vulneráveis que a população ali residente é carente, tornando-se áreas altamente de risco e de desigualdades ambientais. Segundo Dantas e Costa, a desigualdade ambiental se expressa em: 
desigualdade de acesso às condições de vida urbana, pois as populações com menor poder aquisitivo tendem a localizar-se nas chamadas áreas de risco, ou seja, áreas de maior exposição a situações insalubres (contaminação de água, do solo, do ar) e inseguras (riscos de acidentes de diversos tipos. (DANTAS; COSTA, 2009, p. 147)

Devemos salientar que, após essa catástrofe descomunal para o município, a configuração urbana foi reestruturada. Os moradores que sofreram com a enchente de 2010, ficaram cerca de três anos residindo em barracas de lona, sem nenhuma segurança e infraestrutura adequada. Nesse intervalo, o governo Federal, juntamente com o Estado e o município, construíram quatro conjuntos habitacionais, o Conjunto Habitacional Newton Pereira Gonçalves, Nova Esperança, Conceição Lyra e José Carrilho Pedrosa, com cerca de 5.001 residências para as famílias desabrigadas que habitavam a planície fluvial do Mundaú quando as águas transbordaram e destruíram suas habitações.

Como resultado da pesquisa, foi confeccionado um mapa no qual se observa a magnitude do transbordamento da água do rio Mundaú no município palmarino. Esse manancial, ao percorrer seu curso normal, encontrou outros subafluentes (os rios Macaco, Canhoto, Cana Brava, dentre outros) da bacia hidrográfica e colocou em estado de alerta todas as ruas dos bairros e povoados que estavam próximos às planícies fluviais que percorrem União dos Palmares (Mapa 3). 
Mapa 3 - Mapa das áreas afetadas pelo transbordamento das águas do rio Mundaú em junho de 2010

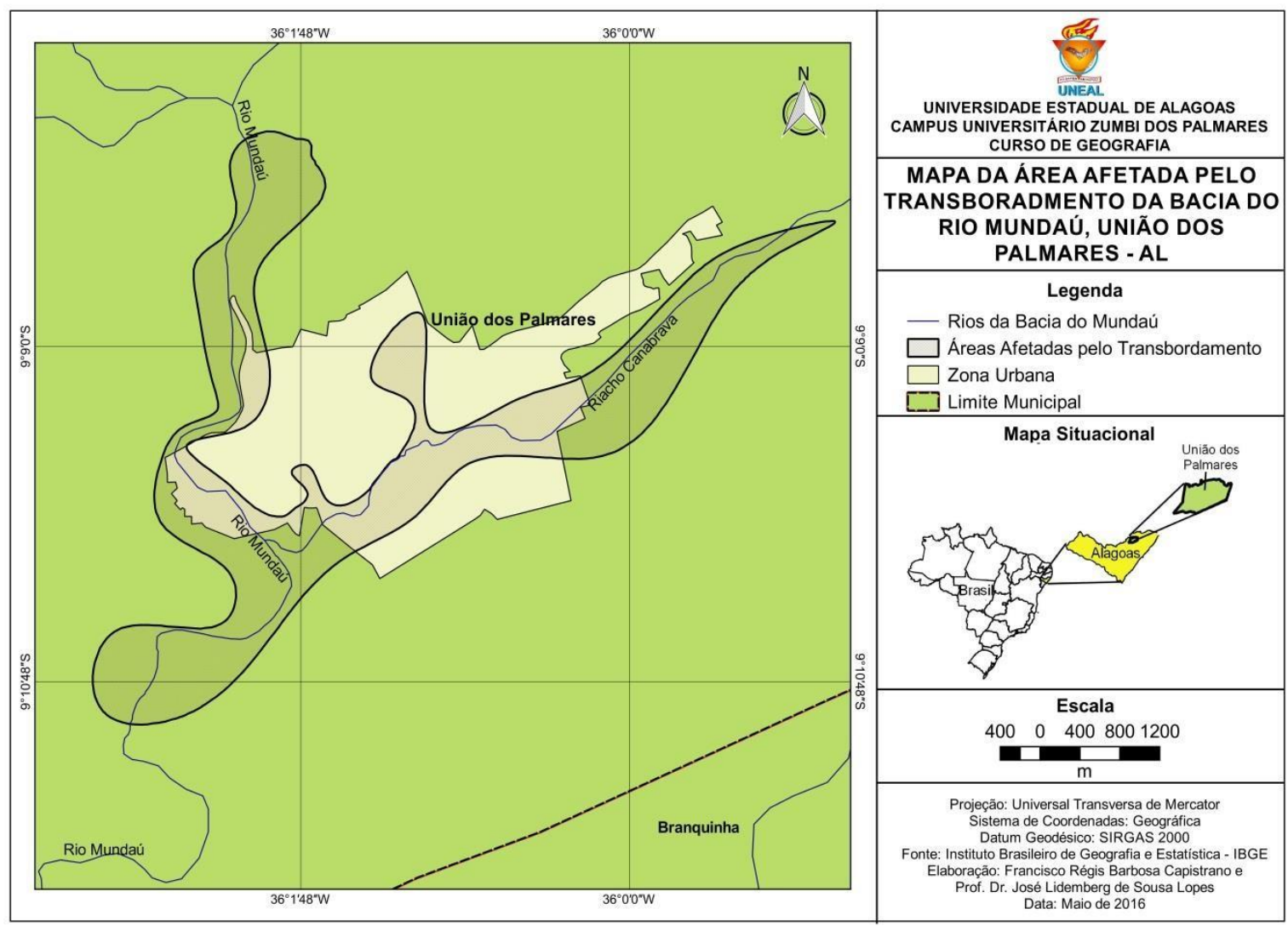

Fonte: Elaborado por José Lidemberg de Sousa Lopes (2016).

Outra importância que se deve levar como contribuição desse mapeamento é a relação de construção de novos conjuntos habitacionais, pois na enchente de 2010 foram construídos dois bairros na cidade de União dos Palmares, entretanto, essas casas só saíram das margens do rio Mundaú, mas estão praticamente nas margens do riacho Cana Brava, subafluente do Mundaú, portanto suscetíveis a novas catástrofes.

Espera-se que os gestores públicos do município se embasem no resultado da pesquisa e, no futuro, englobem ao Plano Diretor o mapa de transbordamento do rio Mundaú, pois constam informações importantes para a prefeitura no que tange às áreas propícias a enchentes, inundações e alagamentos. A confecção de mapa para zoneamento das áreas que foram afetadas pelas águas do rio nessa enchente é um instrumento para a possível solução e prevenção desse tipo de catástrofe, pois demarca 
as áreas que são frágeis para a construção de moradias, indicando a necessidade de que as elas se tornem áreas de preservação permanente, conforme o Código Florestal brasileiro estabelece.

\section{Conclusão}

O estudo da temática da enchente serviu para problematizar e entender os conceitos de desastres, riscos e vulnerabilidade, bem como a pertinência dessas bases conceituais associadas com a dinâmica dos mananciais e o quadro histórico, social e ambiental de Alagoas, em especial do município de União dos Palmares.

Com isso, entender as noções de bacia hidrográfica, enchentes e áreas vulneráveis certamente ajudará os gestores públicos a identificarem áreas onde coexistem riscos sociais e ambientais, isto é, a propor medidas como zoneamento das margens do rio Mundaú proibindo uso e ocupação nessa área.

Há necessidade de entender os condicionantes naturais e a ação indevida do homem em relação ao desmatamento das matas ciliares ao longo das margens de rios para o aumento de áreas agricultáveis, e uso e ocupação dos solos indevidamente por populações carentes. Esses elementos são geradores de problemas sociais e ambientais que, progressivamente, causam assoreamento nos principais rios da região, estendendo as áreas inundáveis nos cursos dos rios para além dos limites naturais de seus leitos maiores.

Em 2010, a ocupação indevida das áreas fluviais do rio Mundaú terminou por atingir justamente as populações lindeiras, para as quais nunca existiu qualquer atenção por parte do poder público. Assim, verificou-se que as populações marginalizadas passaram a ter uma maior exposição à periculosidade, como foi o caso dos moradores das ruas do Jatobá, do Juazeiro e Demócrito Gracindo (conhecida como rua da Ponte), pois esses logradouros foram afetados pelas enchentes, caracterizando-se como áreas de riscos de inundações. 
Por fim, a enchente ocorrida em União dos Palmares deixou a população afetada em condições de vulnerabilidade ainda maior do que antes do desastre. Centenas de pessoas ficaram desabrigadas, desalojadas, além dos enfermos e mortos, prolongandose as precárias condições de vida e saúde. A população afetada, apesar de beneficiada por novas habitações, espera que, no futuro, quando essas inundações ocorrerem, os órgãos gestores promovam estratégias de prevenção, atenção e monitoramento para as áreas geográficas às margens do rio Mundaú. Essas medidas, se bem planejadas, contribuirão para evitar impactos negativos sobre a população, os bens, os serviços e o meio ambiente.

\section{Referências}

ALAGOAS. Enciclopédia municípios de Alagoas. Instituto Arnon de Mello Leonardo Simões: Coordenação Geral. Maceió: Núcleo de Projetos Especiais, 2012.

ALMEIDA, L. Q. de. Vulnerabilidades socioambientais de rios urbanos. Bacia hidrográfica do rio Maranguapinho. Região Metropolitana de Fortaleza, Ceará. 2010. 278 f. Tese (doutorado em Geografia) - Instituto de Geociências e Ciências Exatas, Unesp, Rio Claro, 2010

ALMEIDA, L. Q. de. Vulnerabilidades socioambientais de rios urbanos. Bacia hidrográfica do rio Maranguapinho. Região Metropolitana de Fortaleza, Ceará. 2010. 278 f. Tese (doutorado em Geografia) - Instituto de Geociências e Ciências Exatas, Unesp, Rio Claro, 2010.

Banco Mundial (BM). Avaliação de perdas e danos: inundações bruscas em Alagoas Junho de 2010. Brasília: BM, 2012. Disponível em:

https://www.mdr.gov.br/images/stories/ArquivosDefesaCivil/ArquivosPDF/publicacoes/In undaes-Bruscas-em-Alagoas.pdf. Acesso em: 29 de ago. de 2020

CPTEC/INPE. Centro de previsão do Tempo e Estudos Climáticos. São Paulo, 2010. Disponível em: http://www.cpetc.inpe.br. Acesso em: 25 de nov. de 2015.

DANTAS, E. W. C; COSTA, M. C. L. Vulnerabilidade socioambiental na região metropolitana de Fortaleza. Fortaleza: UFC, 2009. 
DESCHAMPS, M. V. Vulnerabilidade socioambiental na região metropolitana de Curitiba/PR. 2004. Tese (Doutorado em Meio Ambiente e Desenvolvimento) Universidade Federal do Paraná, Curitiba, 2004.

FRAGOSO JUNIOR, C. R. et al. Reflexões sobre a cheia de junho de 2010 nas bacias do rio Mundaú e Paraíba. In: SIMPÓSIO REGIONAL BRASILEIRO DE RECURSOS HÍDRICOS, 10., 2010, Fortaleza. Anais [...]. $\quad$ Fortaleza: [s.n.], 2010. Disponível em: http://www.ctec.ufal.br/professor/vap/Cheia2010.pdf. Acesso em: 01 dez. 2019.

GUERRA, A. T. Dicionário geológico-geomorfológico. 2. ed. Rio de Janeiro: IBGE 1978.

IBGE. Censo demográfico 2000: características gerais da população: resultados da amostra. Rio de Janeiro: IBGE, [2010]. Disponível em:

http://www.ibge.gov.br/home/estatistica/populacao/cens02010/default_resultados_amo stra.shtm. Acesso em: 30 fev. 2020.

KAZTMAN, R.; FILGUEIRA, F. As normas como bem público e privado: reflexões nas fronteiras do enfoque "ativos, vulnerabilidade e estrutura de oportunidades" (Aveo). In: CUNHA, José Marcos P. da (org.). Novas metrópoles paulistas: população, vulnerabilidade e segregação. Campinas: Nepo: Unicamp, 2006.

LOPES, J. L. de Sousa. Proposta de indicadores de sustentabilidade aplicado para o estudo da vulnerabilidade da comunidade de Batoque-Aquiraz/CE. 2013. Tese (Doutorado em Geografia) - Curso de Geografia, Universidade Federal do Ceará, Fortaleza, 2013.

PENNA, N. A. FERREIRA, I. B. Desigualdades socioespaciais e áreas de vulnerabilidades nas cidades. Revista Mercator, Fortaleza, n. 3, v .13, p. 25-36 set./dez. 2014. Disponível em: http://www.mercator.ufc.br/mercator/issue/view/RMv13n3. Acesso em: 29 ago. 2020. DOI: 10.4215/RM2014.1303.0002.

PIRES, J. S. R et al. A utilização do conceito de bacia hidrográfica para a conservação dos recursos naturais: conceitos de bacias hidrográficas: teorias e aplicações. Ilhéus: Editus, 2002. p. 17-35. Disponível em: http://www.uesc.br/editora/livrosdigitais2015/ conceitos_de_bacias.pdf. Acesso em: 29 ago. 2020.

SEMARH - Secretária Estadual de Meio Ambiente e Recursos Hídricos. [Maceió: SEMARH, 2012]. Disponível em: http://www.semarh.al.gov.br/. Acesso em: 29 fev. 2020.

SHIBABUKU, P. Enchente e Inundações urbanas: um espetáculo de erros e irresponsabilidades!. 25 nov. 2018. Il. color. Disponível em: https://noticias.botucatu.com.br/2018/11/25/opiniao-enchentes-e-inundacoes-urbanasum-espetaculo-de-erros-e-irresponsabilidades/. Acesso em: 29 ago. 2020. 
SOUZA, L. B; ZANELLA, M. E. Percepções de riscos ambientais: teoria e aplicações. 1. ed. Fortaleza: Edições UFC, 2010.

TUCCI, C. E. M. Águas urbanas. Estudos avançados, São Paulo: USP, v. 22, n. 63, 2008. Disponível em: http://www.scielo.br/pdf/ea/v22n63/v22n63a07.pdf. Acesso em: 29 fev. 2020.

WALTER, B. M., MILAN, P. Cenário de tsunami no Nordeste. 21 de jun. 2010. II. color. Disponível em: https://www.gazetadopovo.com.br/vida-e-cidadania/cenario-de-tsunamino-nordeste-1dvohyhgmblfjl91colokgxu6/. Acesso em: 29 set. 2019.

Recebido em: 08/04/2020 Aprovado em: 17/09/2020

Universidade do Estado de Santa Catarina - UDESC Centro de Ciências Humanas e da Educação - FAED PerCursos

Volume 21 - Número 46 - Ano 2020 revistapercursos@gmail.com 